\title{
The Effect of Refrigerant Charge on the Performance of a Split-Unit Type Air Conditioner Using R22 Refrigerant
}

\author{
Mohd Hazwan Yusof ${ }^{1,}{ }^{*}$, Sulaiman Mohd Muslim², Muhammad Fadhli Suhaimi ${ }^{1}$, Hassan \\ Ibrahim $^{1}$, Azizuddin Abdul Aziz ${ }^{1}$ and Mohamad Firdaus Basrawi ${ }^{1}$ \\ ${ }^{1}$ Faculty of Mechanical Engineering, Universiti Malaysia Pahang, 26600, Pekan, Pahang. \\ ${ }^{2}$ Engineering Services Division, Ministry of Health Malaysia, Aras 3-7, Blok E3, Kompleks E, Presint \\ 1, Pusat Pentadbiran Kerajaan Persekutuan, 62590 Putrajaya, Malaysia.
}

\begin{abstract}
Numerous air conditioners are running without a proper refrigerant charge due to leakage and improper charging during installation. Therefore, there is a need to understand the performance of the air conditioner if it is not properly charged for the means of optimal operation and cost saving. This study is focusing on the usage of a used small capacity split-unit type air conditioner using R-22 refrigerant. The objective is to study the condenser performance over a variation of refrigerant charges. From the results, it is clear that the optimum refrigerant charge is $100 \%$. The highest cooling capacity and COP were $3,330 \mathrm{~J} / \mathrm{s}$ and 3.05 respectively.
\end{abstract}

\section{Introduction}

One of the appliances that consume a huge amount of energy in everyday life is an air conditioner. Nowadays, the air conditioner can be seen operating everywhere on the planet, from residential, commercial as well as industries and the usage has been extensive. It is one of the major electrical energy consuming appliance in residential $[1,2]$. Globally, it accounts for more than $50 \%$ of building energy usage [3]. According to a report by U.S. Department of Energy (2008), the nation's total energy consumed in residential and commercial buildings accounted for $40 \%$ of total U.S. energy used [4]. In residential, the most common air conditioner type used is split-type, mainly because of its simplicity and flexibility [5].

In Malaysia context, the number of an air conditioner installed in residential has increased over the last few decades. The results of national census showed that a total number of households with air conditioner has dramatically increased from 13,000 (1970), 229,000 (1990), 775,000 (2000) and the number is even higher in 2018 [6]. They also reported that a survey done in Johor Bahru in 2009 indicated that $65 \%$ of households owned air-conditioning systems.

The air conditioner is known to be an energy-intensive appliance that is essential to human's comfort. One of the primary parameters that influences the energy consumption of the air conditioner beside having high efficiency compressor is the amount of refrigerant

\footnotetext{
*Corresponding author: mohdhazwan@ump.edu.my
} 
charge [7-11]. Any discrepancy from the optimal charge will degrade air conditioner performance as well as deteriorate the system's reliability $[1,7,8,12,13]$. Domanski et al. found that systems that run with $30 \%$ undercharged of refrigerant used as much as 17 to $23 \%$ energy [14].

Majority of the cooling appliances are running without a proper refrigerant charge due to leakage and improper charging during installation. It is common that the refrigerant charge in the air conditioning system is not at the optimal level. This is due to improper charging during installation and leakage over its operation. Proctor sum up based on tests of more than 4,000 residential cooling system in California, $62 \%$ are improperly charged [15]. Meanwhile, Domanski et al. highlighted that only $18 \%$ of systems installed in the United States had the correct refrigerant charge [14]. The optimal level of refrigerant charge is determined in accordance with the cooling capacity of a refrigeration system $[8,16,17]$. The system performance is always linked to the appropriate refrigerant mass charge into the system [18].

The information from the appliance's catalogue mainly indicates the approximate weight of refrigerant to be charged and did not determine the performance of the unit with different refrigerant charge. Previous studies by researchers concluded that undercharge or overcharged system would have a significant impact on the performance and causing it to operate with higher electrical input to produce a cooling effect. Therefore, there is a need to understand the performance of the air conditioner if it is not properly charged for the means of optimal operation and cost saving.

All of these researches used a large capacity air conditioner. Therefore, in this research, a small capacity split-unit type air conditioner using R22 refrigerant is used to determine the effect of improper refrigerant charge on its performance. The results of total cooling capacity, total electric power consumption, and coefficient of performance will be presented.

\section{Methodology}

The experiment setup was designed and fabricated by using a split-unit air conditioner, relevant equipment and accessories. Experiment work was performed by setting up the system with the determined input value (refrigerant charge and outdoor temperature settings). The experiment was repeated for all pre-determined settings. Then, all the data obtained was analysed and compared to the previous research works and the data from the manufacturer's data catalogue.

In any performance testing of unitary air-conditioning equipment, the Air-Conditioning \& Refrigeration Institute (ARI) Standard 210/240 has to be applied [19]. All the tests conducted must be in accordance with the test methods and procedures as described in the standard so that the standard ratings can be verified.

However, due to limitations of this research equipment setup (inadequacy of psychrometric room to provide and maintain specific accurate indoor and outdoor temperature), this study could not be performed to the ARI 210/240 standard. Therefore, the results of the study were incomparable to the manufacturer's data sheet and previous works by researchers. Nevertheless, the results would determine the trend and provide information on the effect on the performance of the specific experimental setup. In this study, the airconditioner indoor temperature setting was set to $26^{\circ} \mathrm{C}$ and the blower fan was set at the lowest setting to provide more stable air flow.

The experiment setup was designed as per Fig. 1. In this research, the experiment work utilised a standard $1.5 \mathrm{HP}, 13,000 \mathrm{Btu} / \mathrm{hr}(3.81 \mathrm{~kW}$ cooling) rated used the split-unit type air conditioner (2012 model). The unit used R-22 refrigerant as the working refrigerant gas. The setup included sensors in specific locations to measure parameters such as dry-bulb and wetbulb temperatures, air flow rate, refrigerant pressure (low and high), pipeline temperatures as well as electrical power input. 
To control the outdoor temperature, three-stage coil heaters (1.5 kW each) was used to achieve specific outdoor temperature (see Fig. 2). To measure the air flow rate of the indoor unit, ductwork was attached at the unit's outlet with the dimension of $0.635 \times 0.084 \mathrm{~m}$ crosssection. For the purpose of high-pressure side's reading, the modification was done by installing a port for manifold gauge attachment.

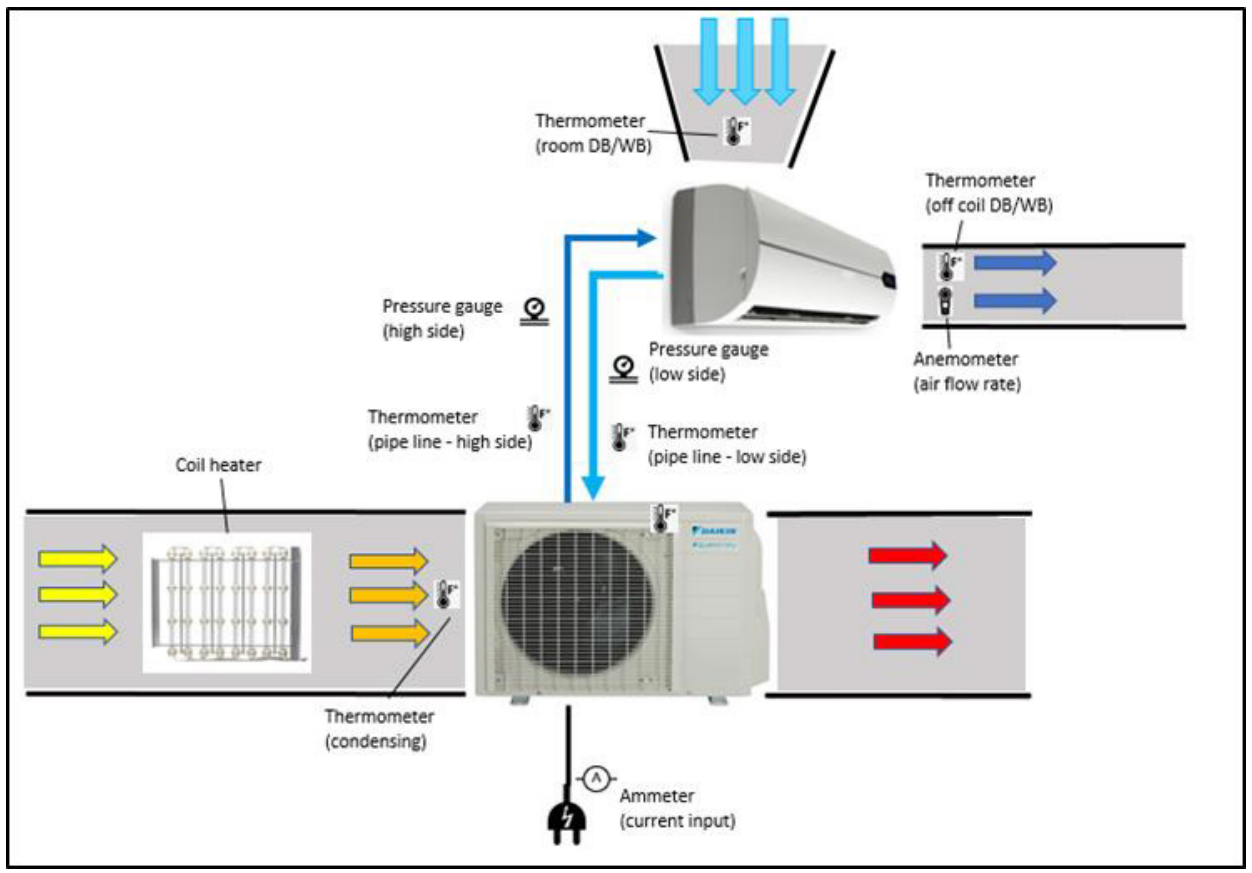

Fig. 1. Schematic diagram of the experiment setup.

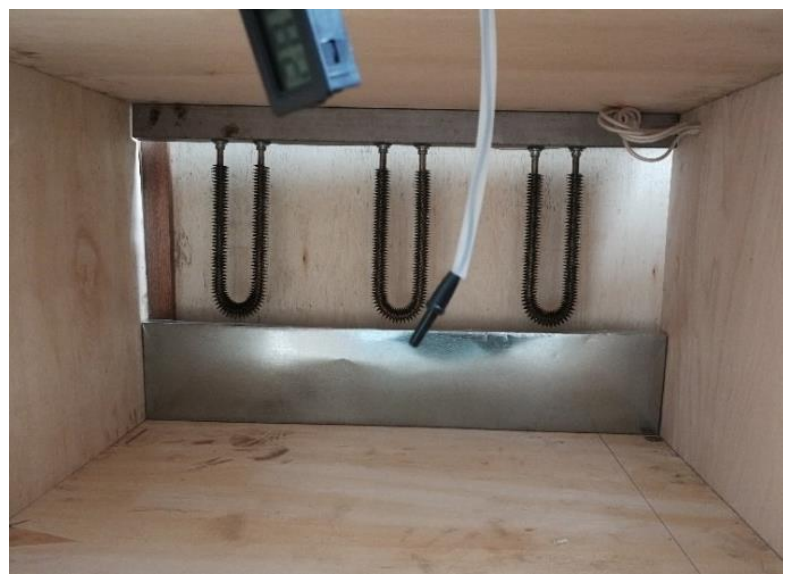

Fig. 2. Three stages of coil heater installed in the outdoor unit's ductwork.

In this research, 9 different refrigerant charges and constant outdoor temperatures were used, as shown in Table 1. 
Table 1 Parameters of refrigerant charge and outdoor temperature.

\begin{tabular}{|l|l|}
\hline Refrigerant charge, $[\%]$ & $\begin{array}{l}80,85,90,95,100,105, \\
110,115,120\end{array}$ \\
\hline Outdoor temperature, $T_{o}\left[{ }^{\circ} \mathrm{C}\right]$ & 30 \\
\hline
\end{tabular}

\section{Performance indicators}

To quantify the performance of the air conditioner in the experiment work, three variables are used: total cooling capacity $\left(C_{T}\right)$, total electric power consumption, and coefficient of performance $(C O P)$.

The calculation of total cooling capacity $\left(C_{T}\right)$ will be using the measurement of air-side of the evaporator [20]. Total capacity is determined by using Equation (1) [20]. Since the cooling on the evaporator involves both sensible and latent heat, the equation is:

$$
C_{T}=V F R \times \rho_{\text {air }} \times \Delta h[\mathrm{~W}]
$$

Here, $V F R$ is the volume air flow rate, $\rho_{\text {air }}$ is air density, and $\Delta h$ is the enthalpy change.

The total electric power consumption $(T E P C)$ is determined by using Equation (2) [20]. In single-phase power,

$$
T E P C=\frac{V \times A \times P F}{1000 \quad[\mathrm{~W}]}
$$

Here, $V$ is voltage, $A$ is current, and $P F$ is power factor.

The coefficient of performance $(C O P)$ is defined as the total cooling capacity divided by the work of the compressor, as shown in Equation (3) $[19,21]$.

$$
C O P=\frac{C_{T}}{T E P C}
$$

\section{Results and discussions}

The result of total cooling capacity $\left(C_{T}\right)$ as a function of refrigerant charge is shown in Fig. 3. At $80 \%$ charge, the total cooling capacity was at the lowest point. Generally, all the $\left(C_{T}\right)$ figures were lowest for all outdoor temperatures at this charge. The $C_{T}$ increased with the increase of refrigerant charge and peaked at $100 \%$ charge $\left(3,330 \mathrm{~J} / \mathrm{s}\right.$ at $30^{\circ}$ outdoor temperature). Then the figure declined in overcharged conditions $(>100 \%)$. The slope of the $C_{T}$ at undercharged conditions was steeper than at overcharged conditions.

At undercharged conditions $(<100 \%)$, the $C_{T}$ dropped, caused by the reduction of refrigerant flow rate. The suction temperature trend remained fairly constant, showing there was not much effect on the compressor efficiency throughout the refrigerant charge reduction. Meanwhile, at overcharged conditions (>100\%), the cooling capacity dropped with the increase of refrigerant charge. These trends were relatively similar as reported in previous studies by Houcek et al. [22], Mohsen Farzad et al. [1] and J.M. Choi et al. [8]. Compare to the peak value at $100 \%$ charge, the $C_{T}$ dropped $17.7 \%$ at $80 \%$ charge, and $11.4 \%$ at $120 \%$ charge, respectively. 


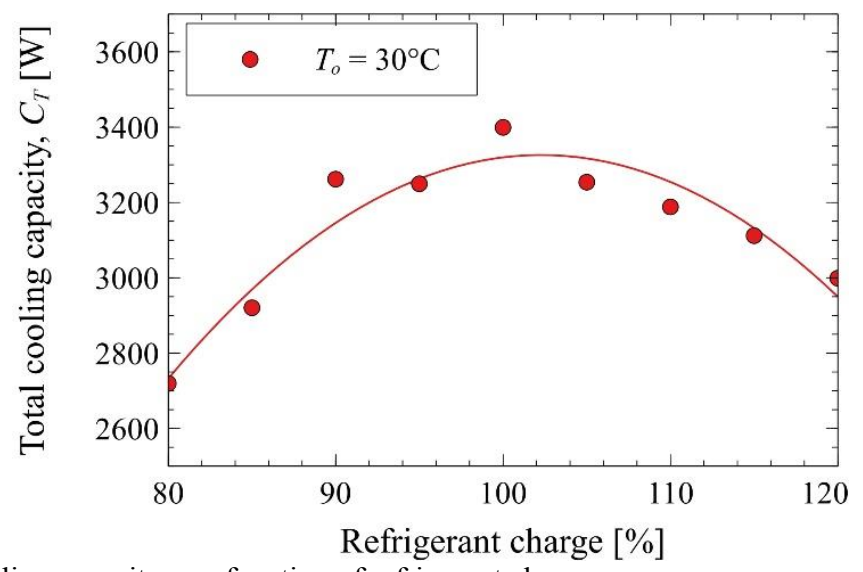

Fig. 3. Total cooling capacity as a function of refrigerant charge.

Meanwhile, as shown in Fig. 4, the total electric power consumption (TEPC) increased steadily throughout the increase of the refrigerant charge. This trend explained the increase of power input required as the work of the compressor increased due to the addition of the refrigerant. In this work, the reading was the combination of power consumed by both outdoor and indoor units. The highest TEPC obtained was $1,164 \mathrm{~W}$ for $120 \%$ refrigerant charge.

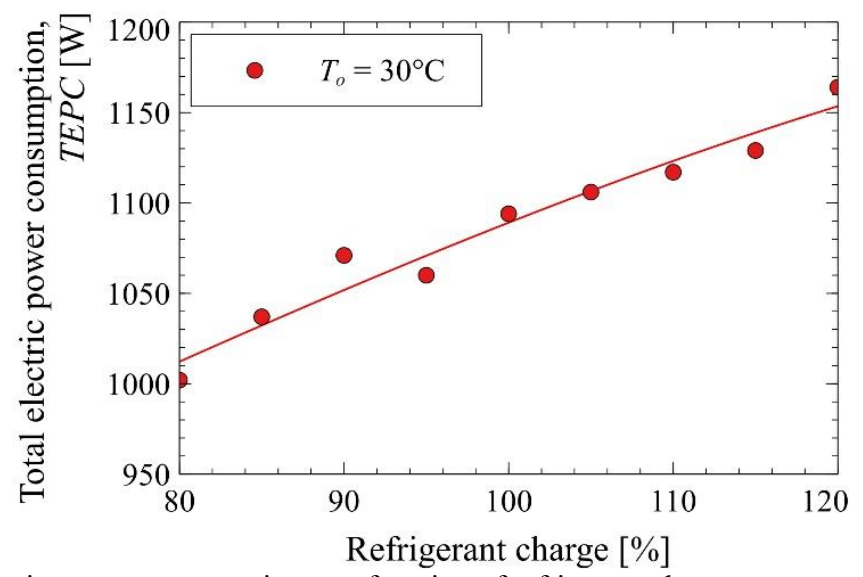

Fig. 4. Total electric power consumption as a function of refrigerant charge.

As for the coefficient of performance $(C O P)$, the result is shown in Fig. 5. It was found that the $C O P$ reduced with undercharged and overcharged conditions, and the slopes for both were fairly similar. The $C O P$ also peaked at $100 \%$ charge $\left(3.05\right.$ at $30^{\circ} \mathrm{C}$ outdoor temperature). The trend was almost similar to the $C_{T}$ trend as a function of the refrigerant chart (Fig. 3), but the slopes were steeper at overcharged conditions since the total electric power consumption $(T E P C)$ kept increasing with the increase of refrigerant charge. Comparing with the COP at $100 \%$ refrigeration charge, the COP at $80 \%$ charge dropped $10.8 \%$, and at $120 \%$ charge dropped $16.4 \%$, respectively. 


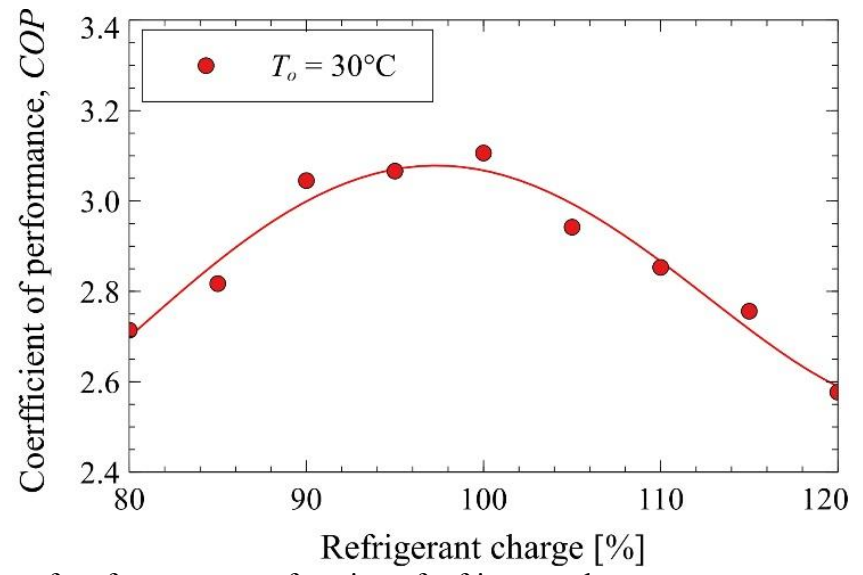

Fig. 5. Coefficient of performance as a function of refrigerant charge.

\section{Conclusion}

The present work emphasises on determining the performance of the air conditioner over a variation of refrigerant charges. As previously highlighted, since the experiment work was not conducted in accordance with the ARI 210/240 standard, the results could not be compared directly to the manufacturer's data and previous works by researchers. However, it provides information on how the system performs and react with an improper refrigerant charge. The conclusions are as follows:

1. The condenser performance of the air conditioner maxed at $100 \%$ refrigerant charge. The highest cooling capacity and $C O P$ were $3,330 \mathrm{~J} / \mathrm{s}$ and 3.05 respectively.

2. The total cooling capacity $\left(C_{T}\right)$ and $C O P$ dropped with undercharged as well as the overcharged system. Comparing with $100 \%$ refrigerant charge, for $80 \%$ system, $C_{T}$ and $C O P$ dropped by $17.7 \%$ and $10.8 \%$ respectively whereby for $120 \%$ system, the $C_{T}$ and $C O P$ dropped by $11.4 \%$ and $16.4 \%$ respectively.

This research was supported by the Ministry of Higher Education and Universiti Malaysia Pahang under grant scheme FRGS/1/2017/TK10/UMP/02/18 and RDU170137.

\section{References}

1. D. L. O. Mohsen Farzad, Rep. Energy Syst. Lab. Res. Consort. (1988).

2. D. L. O. Mohsen Farzad, Energy Build. 14, 363 (1990).

3. Y. H. Jiangyan Liu Juanxin Chen, Jiangyu Wang, Guannan Li, Wenju Hu, Appl. Therm. Eng. 107, 284 (2016).

4. U. D. Of Energy, Energy Efficiency Trends in Residential and Commercial Buildings (2008).

5. M. A. S. S.A. Nada, Appl. Therm. Eng. 123, 874 (2017).

6. S. J. Tetsu Kubota Doris Hooi Chyee Toe, Dilshan Remaz Ossen, J. Int. Dev. Coorperation 17, 61 (2011).

7. B. D. D. Springer, Build. Technol. Progr. (2013).

8. C. Jongmin, K. Yongchan, Energy 27, 391 (2002). 
9. D. Y. Mehdi Mehrabi, Build. Simul. (2017).

10. D. Y. Mehdi Mehrabi, Int. J. Refrig. 76, 367 (2017).

11. B. Michael, P. John, P. George, D. Tom, Final Rep. (1996).

12. H. S. P. Dong Ho Kim Min Soo Kim, Int. J. Refrig. 40, 254 (2014).

13. J. E. B. Woohyun Kim, Int. J. Refrig. 35, 1805 (2012).

14. H. H. Piotr A. Domanski W. Vance Payne, Appl. Therm. Eng. 90, 352 (2015).

15. T. D. John Proctor, Proc. ACEEE 2002 Summer Study Energy Effic. Build. 1, 53 (2002).

16. N. Leon, L. O. Dennis, 189 (1992).

17. D. L. O. Mohsen Farzad, Int. J. Refrig. 14, 321 (1991).

18. H. M.-T. F. Poggi D. Leducq, A. Bontemps, Int. J. Refrig. 31, 353 (2008).

19. A.-C. \& R. I. (ARI), Stand. 210/240 (2006).

20. A. A. B. Jr., (2007).

21. D. Micallef, (2014).

22. M. T. John Houcek, Proc. First Symp. Improv. Build. Syst. Hot Humid Clim. (1984). 